\title{
ANNOUNCEMENTS
}

\section{PAUL GUGGENHEIM FOUNDATION}

As a tribute to the memory of Paul Guggenheim, a Foundation bearing his name has been set up in Geneva, Switzerland. Its purpose is to award periodically a prize, to be known as the "Paul Guggenheim Prize" and to be accompanied by a financial reward, to the author of an outstanding work in the field of public international law.

At its meeting of February 22nd, 1979, the Board of the Foundation adopted the following Rules.

1. The Paul Guggenheim Prize is awarded by the Paul Guggenheim Foundation to a work of public international law of outstanding importance and quality, which is the first major work of its author.

The time-limit for submission shall be set by the Board of the Foundation so that a prize may be given, if appropriate, every two years.

2. Works may be submitted to the jury either in the form of published books or in the form of manuscripts destined for publication. Works which have already received an international prize of a similar nature shall not be considered.

3. Works may be in one of the following languages: English, French, German, Italian, Spanish.

4. Works shall be sent in five copies to the Paul Guggenheim Foundation, c/o The Graduate Institute of International Studies, 132 rue de Lausanne, 1211 Geneva 21 , Switzerland.

5. The jury may select a work which was not submitted for the prize by its author and which was not published more than two years before the time-limit set for entries.

6. The successful manuscript shall be published by the author with a mention of the award received; the published text shall be strictly consistent with the text submitted to the jury.

Such consistency shall be certified by a declaration of the president of the jury. The president of the jury may authorize the author to make such changes as are justified in the light of events or scientific developments which have occurred since the award was made.

7. The prize-giving ceremony shall take place at a special meeting of the Board of the Foundation in Geneva, at The Graduate Institute of International Studies. The jury's decision awarding the prize shall be notified to major journals of international law for publication.

8. The jury may decide not to award the prize.

The Board of the Foundation set the time-limit for the first submission at June 30th, 1980. 